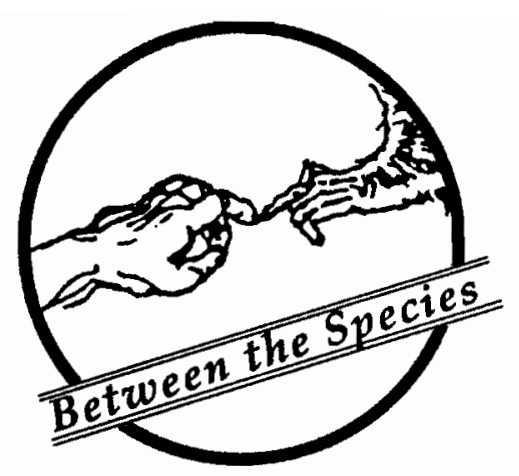

\title{
THE ADOLESCENT AS ENVIRONMENTAL ETHICIST
}

\author{
Julie J. Dunlap \\ Humane Society of the United States
}

Editors' Note: This essay by Dr. Dunlap and the response to it by Professor Pluhar were presented at the Eastern Division Meeting of the Society for the Study of Ethics and Animals, held in Washington, D.C., in December, 1988.

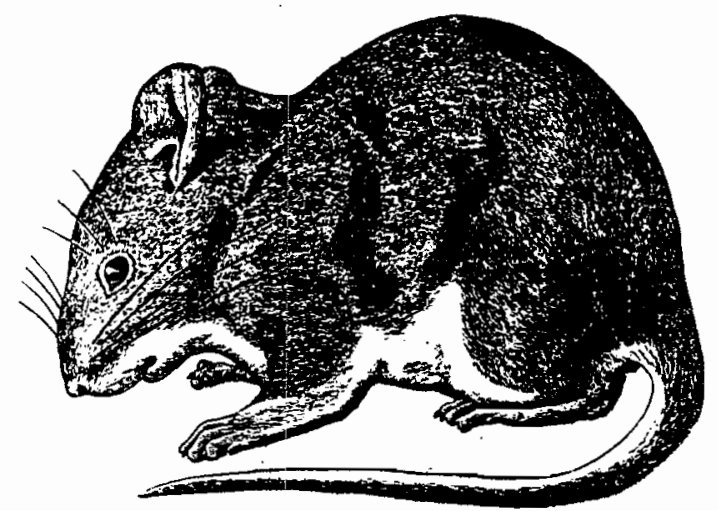

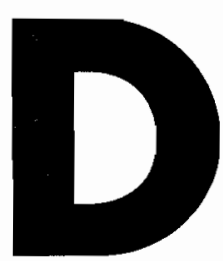

evelopmental psychologists have revolutionized our understanding of childhood by demonstrating that children can think like philosophers. Developmental research has shown that children at every development level actively seek to understand their world, addressing questions of time, causality, space, and cosmology just as philosophers do. In early childhood, however, children's reasoning abilities limit their abilities to think in the formal philosophical sense. It is not until adolescence that most children develop the capacities to reason abstractly, to study the relationships between ideas, and to reflect consciously on questions about themselves and the universe. For example, their new abilities allow

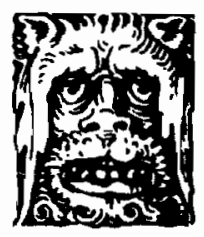

PSYCHOLOGY/ HUMANE EDUCATION 
comprehension of taxonomic classification systems and theories of ecological interactions, making possible fresh insights into the relationships between humans and nonhuman species and natural communities. In addition, the reasoning advances of adolescence give children a more encompassing understanding of moral values, and they can begin to reflect deliberately on rights and values as related to individuals and to societies.

The simultaneous emergence of abilities to understand interspecies and ecological relationships and to deliberate on complex moral issues is tantalizing. Can adolescents apply their new capacities to understand moral conflicts related to nonhuman animals and natural environments? I address the questions by exploring the psychological basis of humans' ethical relationships with their environments, focusing on moral reasoning about nonhuman animal treatment. The present paper uses the findings of my study of adolescents' moral reasoning about animal treatment to support an argument that adolescents can reason about ethical questions related to nonhumans and nature. ${ }^{1} \mathrm{By}$ asking boys between twelve and eighteen years of age to resolve animal treatment dilemmas, the project obtained the first evidence suggesting that adolescents can think like humane and environmental ethicists.

\section{Moral Development Theory}

Lawrence Kohlberg and his colleagues have spent several decades following changes in individuals' moral reasoning patterns throughout the lifespan. ${ }^{2}$ Kohlberg argues that each child's experiences with increasingly diverse and complex social situations and moral conflicts compel him to develop more flexible and sophisticated moral thought processes. He contends that moral reasoning progress involves qualitative changes in the child's reasoning structures, or stages. Kohlberg defines a six stage model of moral development and claims that each stage represents a qualitatively different pattern of thought that all children progress through in an invariant sequence, stimulated by interactions with their social environment.
To test his model Kohlberg conducts intensive analyses of individuals' responses to hypothetical moral dilemmas. ${ }^{3}$ For example, in the wellknown Heinz dilemma a woman is dying of cancer. Her husband, Heinz, is faced with a choice of stealing a drug to save her life or obeying the law and allowing her to die. Kohlberg does not focus on what each person thinks Heinz should do, because subjects at any stage can defend either action choice. Instead, he examines the moral logic used to defend each subject's decision. The reasoning an individual uses to justify either stealing or obeying the law reflects his or her stage of moral development.

Kohlberg describes the moral reasoning of a young stage 1 or 2 child as simple and inflexible, following specific rules based on the demands of authorities such as parents or God or on concrete personal needs. For example, a stage 1 child might oppose stealing because a parent said it was wrong, while a stage 2 thinker might argue for stealing because Heinz needs his wife to help him survive. As the child reaches stage 3 or 4 in adolescence, his or her reasoning becomes more complex and flexible. The child can consider, first, the needs and rights of concrete individuals such as family members and, later, the needs or rights of more abstract individuals within society. A stage 3 adolescent might defend stealing because the family loves the wife, while a stage 4 subject might argue for stealing because the wife plays an important role in society. If an individual achieves stage 5 moral cognitive abilities in adulthood, his or her reasoning will allow sophisticated judgments about the rights of abstract persons in all society. At stage 5, human rights are defined by social contracts that are created and accepted by autonomous individuals. A stage 5 subject might justify stealing because the wife or any human has a right to life that should be protected by society. ${ }^{4}$

According to Kohlberg, the endpoint of moral development is stage $6 .{ }^{5}$ Although earlier theory formulations claimed empirical support for stage 6 , Kohlberg now acknowledges that none of his long-term subjects uses stage 6 thinking. He no longer expects most individuals to achieve the highest moral stage, but he believes that a ter- 
minal stage description is essential to a theory aimed at reconstructing the lifespan development of a reasoning process. In the absence of empirical evidence, Kohlberg has defined stage 6 using arguments from moral philosophy, particularly Rawls' theory of justice. Rawls contends that fairness would best be achieved in society by imagining that each member participates in the formation of laws and rules under a veil of ignorance, hiding knowledge of the person's identify, including his age, sex, and social status. ${ }^{6}$ The veil of ignorance frees each person to take objectively the perspective of the other group members and to cooperate toward a universally fair and rational definition of social rights and values. Kohlberg, following Rawls, expects a stage 6 thinker to resolve the Heinz dilemma by using a rationally derived hierarchy of rights and duties to determine which of the conflicting rights claims deserves priority, regardless of situational or personal details. Although rarely achieved, an individual with stage 6 abilities would resolve moral dilemmas using universal justice principles requiring respect for the equal rights and dignity of all humans.

\section{Moral Reasoning About Animals}

Previous research related to Kohlberg's theory has focussed on children's developing moral relations with other humans. However, several authors have speculated on extending Kohlberg's theory to explain the development of ethical reasoning about animals and nature. ${ }^{7}$ Nash, most explicitly, interprets Kohlberg's work as showing that moral development is a process of learning to extend ethical consideration to increasingly remote and abstract individuals and communities. He suggests that an individual's next logical developmental step after achieving stage 6 recognition of universal human rights may be to acknowledge the rights of nonhuman animals and, still later, species and ecosystems. However, Kohlberg's findings indicate that stage 6 abilities are rarely achieved, perhaps only by moral leaders such as Gandhi or King. Accepting the belief that humane and environmental ethics develop after stage 6 would entail expecting persons extending moral consideration to animals and nature to be more rare than humans like Gandhi or King.

If moral consideration of nonhuman individuals and natural communities is a more common phenomenon, ethical reasoning about nonhumans must develop concurrently rather than after moral reasoning about humans. Concurrent development, in fact, appears more logical. Nash sees children's ethical systems as expanding from concrete, close relationships to include abstract, remote associations, but he fails to see that humans can be closer, in some cases, to animals than to other humans. For over 12,000 years, domestic animals have been integrated into human societies as symbols of wealth and power and as sources of food, energy, companionship and beauty. ${ }^{8}$ Although individuals' contacts with wild animals and natural areas have declined in many cultures, each person encounters and may develop attachments to a variety of nonhuman organisms, starting in childhood with pets and mythical beasts. It seems likely that young children, in their efforts to understand their surroundings, seek ethical definitions of their relationships with close animals as well as humans and that their ethical reasoning progresses through successive stages of enhanced abilities to consider more remote and abstract animals and natural communities as well as humans and human societies.

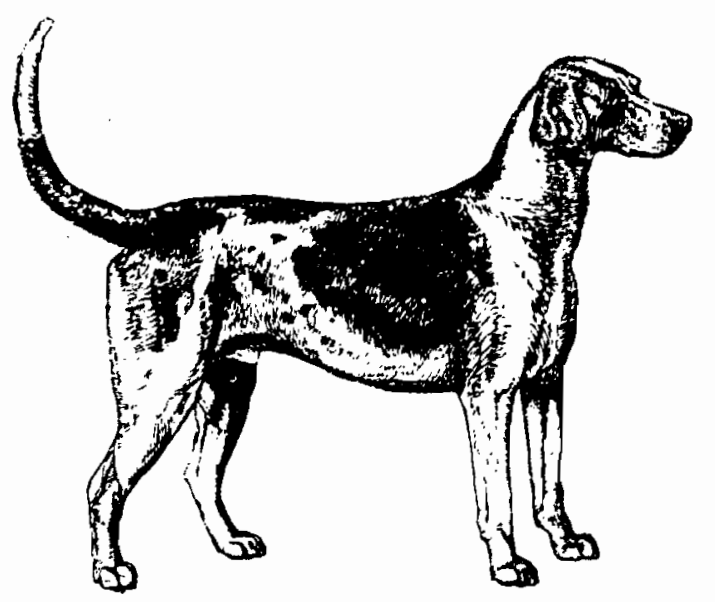


Table 1. Stage Score Distributions for Each Human or Animal Reasoning Type (Number and Percent of Subjects at Each Stage; $N=81$ ).

Human Heinz Story

$\begin{array}{ccr}\text { Stage } & \mathrm{n} & \% \\ 1 & 0 & 0.0 \\ 1 / 2 & 0 & 0.0 \\ 2 & 8 & 9.9 \\ 2 / 3 & 20 & 24.7 \\ 3 & 34 & 42.0 \\ 3 / 4 & 15 & 18.5 \\ 4 & 4 & 4.9 \\ 4 / 5 & 0 & 0.0\end{array}$

Chimpanzee Heinz Story

\begin{tabular}{ccr}
1 & 2 & 2.5 \\
$1 / 2$ & 2 & 2.5 \\
2 & 25 & 30.9 \\
$2 / 3$ & 21 & 25.9 \\
3 & 18 & 22.2 \\
$3 / 4$ & 10 & 12.3 \\
4 & 3 & 3.7 \\
$4 / 5$ & 0 & 0.0 \\
\multicolumn{3}{c}{ Dog Heinz Story }
\end{tabular}

$\begin{array}{ccr}1 & 0 & 0.0 \\ 1 / 2 & 0 & 0.0 \\ 2 & 19 & 23.5 \\ 2 / 3 & 28 & 34.6 \\ 3 & 24 & 29.6 \\ 3 / 4 & 9 & 11.1 \\ 4 & 1 & 1.2 \\ 4 / 5 & 0 & 0.0\end{array}$

Turkey Heinz Story

$\begin{array}{ccr}1 & 0 & 0.0 \\ 1 / 2 & 5 & 6.2 \\ 2 & 33 & 40.7 \\ 2 / 3 & 25 & 30.9 \\ 3 & 13 & 16.0 \\ 3 / 4 & 5 & 6.2 \\ 4 & 0 & 0.0 \\ 4 / 5 & 0 & 0.0\end{array}$

Human Doctor Story

$\begin{array}{ccr}\text { Stage } & \mathrm{n} & \% \\ 1 & 0 & 0.0 \\ 1 / 2 & 0 & 0.0 \\ 2 & 8 & 9.9 \\ 2 / 3 & 27 & 33.3 \\ 3 & 34 & 42.0 \\ 3 / 4 & 7 & 8.6 \\ 4 & 5 & 6.2 \\ 4 / 5 & 0 & 0.0\end{array}$

Chimpanzee Doctor Story

\begin{tabular}{ccr}
1 & 0 & 0.0 \\
$1 / 2$ & 3 & 3.7 \\
2 & 17 & 21.0 \\
$2 / 3$ & 23 & 28.4 \\
3 & 29 & 35.8 \\
$3 / 4$ & 9 & 11.1 \\
4 & 0 & 0.0 \\
$4 / 5$ & 0 & 0.0 \\
\multicolumn{3}{c}{ Dog Doctor Story }
\end{tabular}

$\begin{array}{ccr}1 & 0 & 0.0 \\ 1 / 2 & 1 & 1.2 \\ 2 & 16 & 19.8 \\ 2 / 3 & 30 & 37.0 \\ 3 & 30 & 37.0 \\ 3 / 4 & 4 & 4.9 \\ 4 & 0 & 0.0 \\ 4 / 5 & 0 & 0.0\end{array}$

Turkey Doctor Story

$\begin{array}{ccr}1 & 0 & 0.0 \\ 1 / 2 & 1 & 1.2 \\ 2 & 19 & 23.5 \\ 2 / 3 & 27 & 33.3 \\ 3 & 31 & 38.3 \\ 3 / 4 & 3 & 3.7 \\ 4 & 0 & 0.0 \\ 4 / 5 & 0 & 0.0\end{array}$


To address the question of how adolescents reason about animal treatment, I interviewed secondary school students using methods modeled after Kohlberg's. The study sample included 81 boys from junior and senior high schools in Connecticut. The two age groups selected were 12 - 14 year olds (eighth graders) and $16-18$ year olds (twelfth graders). Only males were included based on the arguments of Gilligan that Kohlberg's theory and methods are inadequate to describe female moral development. ${ }^{9}$ Studying only boys' reasoning preserved the validity of the methods while allowing interpretation of ethical reasoning about animals in relation to Kohlberg's longitudinally-supported moral development theory. However, it must be recognized that the results of this study of males' justice reasoning should not be generalized to interpret females' moral thinking about either humans or animals.

Each boy was personally interviewed at his school. Two types of instruments were used to explore the boys' moral reasoning. The first instrument, focusing on moral reasoning about humans, included two of Kohlberg's standard moral dilemmas. One human story was the Heinz dilemma, which involves a conflict over whether or not a man should steal to save his wife's life. The other human story was Kohlberg's Doctor dilemma, which involves a conflict over whether or not a doctor should break the law to euthanize a woman who is dying painfully. Each human dilemma was followed by a series of questions designed by Kohlberg to help the subject articulate his moral ideas.

The second instrument, focusing on moral reasoning about animals, included original animal dilemmas that were constructed to be equivalent to the human Heinz and Doctor stories. For example, one Heinz form of an animal story concerns a dilemma over whether or not a boy should steal to save a wild chimpanzee's life. One Doctor form of an animal story presents a conflict over whether or not a veterinarian should euthanize a pet dog without the owner's permission. A Heinz and a Doctor story form were constructed for each of three different types of animals: wild chimpanzees, pet dogs, and farm turkeys. Each animal story was followed by a series of questions based on the probes following the corresponding human dilemma. In addition, animal stories were followed by questions aimed at exploring how an animal's rarity or endangered status might influence each boy's reasoning.

The subjects' responses to the human Heinz and Doctor dilemmas were analyzed using Kohlberg's detailed scoring system. ${ }^{10}$ The system focuses on the moral logic behind each response, and response scores were used to calculate a stage score for each boy for each dilemma. An equivalent system, emphasizing moral logic, was developed for scoring the animal dilemma responses. Each boy received stage scores for the Heinz and the Doctor forms of each type of animal dilemma, for a total of six scores of animal reasoning per subject.

The stage score distributions for each reasoning type for the sample population are summarized in Table 1. Moral reasoning stage scores can theoretically range from stage 1 to stage 5 , but in this study the subjects' human reasoning scores ranged only from stage 2 through stage 4 on both the Heinz and the Doctor story forms. Both stage 1 respect for authority and stage 5 social contract reasoning were absent from boys' human dilemma responses. Instead, the boys used egocentric stage 2 thinking, group-oriented stage 3 reasoning, or society-oriented stage 4 thinking to solve human dilemmas. The stage range for the human scores of these subjects is similar to the range found for adolescent males in previous studies. ${ }^{11}$ In response to animal dilemmas, the boys used stage 1 to stage 4 reasoning. As in the human responses, stage 5 thinking was absent from the boys' responses to all types of animal dilemmas. A few boys did use stage 1 thinking, and subjects often used stage 2 or stage 3 reasoning in discussing animal stories. A few others used stage 4 thinking to justify their animal dilemma solutions. Regardless of their level of reasoning, boys used the same moral logic to resolve both human and animal dilemmas as revealed in the following stage descriptions. 


\section{Stage Descriptions}

\section{Stage 1}

Human Reasoning. According to Kohlberg, a stage 1 child has unilateral respect for authority and accepts the moral rules laid down by authority figures. ${ }^{12}$ At stage 1, punishment is an inevitable consequence of disobedience, and avoiding punishment is the major reason for following the commands of authorities. For example, a child may oppose mercy killing due to his focus on authority and punishment. The stage 1 thinker sees euthanasia of humans as morally wrong simply because it has been labeled a crime by authorities. He may also argue that if the Doctor breaks the law to euthanize a person, he can and will be punished.

Animal Reasoning. The logical structure of the boys' stage 1 animal responses was indistinguishable from stage 1 human responses. The subjects' stage 1 respect for authorities is indicated by their acceptance of any law as a moral rule; boys argued against law breaking for animals simply because they said it is wrong or it is a crime. The boys' stage 1 belief in the inevitable consequences of disobedience is similarly reflected in their arguments that no one should steal or euthanize an animal because he will be punished by being arrested or fined.

\section{Stage 2}

Human Reasoning. Unlike a stage 1 child, a stage 2 thinker can take another person's perspective, allowing him to see that each person has interests to pursue and that interests may conflict. At stage 2, the child believes that conflicts should be resolved by an equal, concrete exchange of goods or services. While recognizing the interests of others, however, the stage 2 child defines moral behavior hedonistically and expects morally right actions to satisfy his needs and desires. As a result, the stage 2 child values other persons and objects instrumentally according to how they contribute to his welfare. Stage 2 subjects supported law obedience in both the human Heinz and Doctor stores based on instrumental considerations. For examples, boys argued that neither Heinz nor the Doctor should break the law because of the risk of going to jail, particularly if the dying person had no practical value to him. Pragmatic needs and rights were also used to support saving or euthanizing the woman in each story. Stage 2 boys believed that Heinz or the Doctor should break the law if he needed or liked the woman enough to risk going to jail, especially if she would be pragmatically difficult to replace or would reciprocate his efforts in the future.

Animal Reasoning. The animal responses involved equivalent stage 2 concerns for instrumental value and reciprocal exchange. Risk of punishment remained a major reason for not stealing or euthanizing. If a boy saw little pragmatic value in an animal or rare species, he argued that helping the animal or species was not worth risking trouble for himself. However, boys were willing to risk punishment if they valued the animal in each story. Subjects recognized diverse animal values, such as economic and food values for turkeys, companionship or protective values for dogs, and entertainment or scientific values for chimpanzees. The stage 2 focus on concrete exchange led some boys to argue that the value of animals could include reciprocating humans' moral actions. One subject recommended stealing to save a chimpanzee because "like maybe he's walking in the woods one day and he's attacked by a group of angry chimpanzees. And that monkey happens to be in that group. And he recognizes the guy. He might stop that group from killing him. Like that guy saved his life.'

Concrete exchange arguments were also used to oppose helping animals. Boys used the stage 2 concept of fairness that negative actions should be reciprocated in kind, arguing that any animal that harmed another person or animal deserved to suffer or die. An animal belonging to a harmful species also deserved retributive treatment, even if that individual had not caused the harm. Harmful animals were viewed as having negative human benefits, but even useful animals were accorded little value if they were seen as easily replaced. Unlike humans, animals were sometimes seen as interchangeable. For example, one boy opposed stealing for a turkey, explaining, "A turkey is not really important.... 
There are lots of turkeys, and they can get another one." The subject saw little value in one easily replaced turkey and refused to risk punishment for one member of such a plentiful animal group.

Pragmatic stage 2 interests were frequently reflected in subjects' reasoning about rare animal treatment. For example, stage 2 boys argued that rare animals should be preserved because it would be pragmatically difficult to replace their benefits to humans. In addition, some boys' arguments focused on God's or nature's reasons for creating an animal or a species. The responses reflected an assumption that God or nature would act like a stage 2 child in the same position, creating only useful animals. In these responses boys wished to prevent the deaths of individual animals to avoid wasting their functions and opposed extinction because it permanently prevents fulfilling God's or nature's purpose for the species. However, in other responses, God's or nature's purposes were interpreted as supporting letting animals in either story die. According to these subjects, natural pain, death, and extinction should be accepted because they are planned by God or nature to fulfill specific purposes.

\section{Stage 3}

Human Reasoning. At stage 3 the adolescent has moved beyond his stage 2 definition of justice as reciprocal concrete exchange. Instead, his enhanced abilities to imagine the moral viewpoints of others allow him to resolve moral conflicts by applying the stage 3 justice concept summarized by the Golden Rule, "Do unto others as you would have them do unto you." The stage 3 child expects other moral individuals also to follow the Golden Rule, resulting in group cooperation rather than independent pursuit of self-interests. He defines himself more as a group member than as an individual, and his major motives for moral behavior are group approval and adherence to group norms. Through his concerns for others' feelings, he conforms to group expectations and maintains his concrete connections with members of his immediate community.
Subjects using stage 3 reasoning to resolve human dilemmas focused on concerns for interpersonal affiliation, the feelings of others, and prosocial motives and behaviors. The boys valued loving relationships as ends in themselves rather than for pragmatic benefits, and they expected people in loving relationships to help each other. For example, boys argued that the decision to save or euthanize a woman should be made by someone who loves her and will pursue her best interests. Stage 3 boys' abilities to to see others' perspectives allowed them in the Doctor story to appreciate that the woman's pain distinguished her perspective from that of her husband's or her doctor's. Subjects used their empathetic understanding of the woman's suffering to justify her decision to be euthanized. The stage 3 subjects also used their role taking abilities to assess motives behind dilemma actions. The boys believed that each story character should intend to follow group norms such as helping others. They reasoned that a person's value as a group member declined if he lacked prosocial intentions. For example, boys saw the druggist in the Heinz story as motivated by greed and argued that his failure to help Heinz mitigated the wrongness of stealing. Boys also feared self disapproval, or a guilty conscience, if they failed to behave in prosocial ways toward humans.

Animal Reasoning. Equivalent stage 3 reasoning appeared in the animal dilemma responses. Boys expressed stage 3, nonpragmatic love for all three types of dilemma animals. According to one subject, "You share experiences with your pets, and you almost feel like you can talk to them. You feel like you really know them, and it's almost like dealing with a human rather than a dog." For that boy and others, relationship with animals involved mutual sharing, reciprocal love, and obligations for helping. The responses also revealed abilities to empathize with animals' feelings. Boys who empathized with the suffering animal in the Doctor story forms supported euthanasia, while boys who focused on the feelings of people close to the animal rejected mercy killing if they believed that it would cause the humans pain. Compassion for suffering and other prosocial motives were expected to guide behavior toward 
animals as well as humans. When boys perceived a character as motivated by prosocial desires, such as helping an animal or people who loved the animal, the subjects supported the character's decision either to uphold or break the law. On the other hand, when they judged that a person's motives were self-interested, the subjects censured his behavior. In stage 3 responses anyone with selfish motives should expect to have a guilty conscience, whether his actions harmed a human or an animal.

In contrast to human dilemma responses, stage 3 animal responses revealed that boys often valued and loved groups of animals, not just individuals. Boys noted that humans feel affection for types of animals, and they used human love for animal types to support saving individual animals and for preserving rare species. In valuing animals as groups, stage 3 boys saw connections between animals that implied interdependence. They argued that animals in groups, like humans in communities, are mutually dependent. Subjects contended that individual animals that contribute little to their group or to the human community, such as common animals, have little value and should not be helped. However, rare animals should be saved to preserve the animal community. Subjects who saw animals as also dependent on humans interpreted animal stewardship as an indication of prosocial character. Subjects recognized that humans do behave antisocially toward animals, but they asserted that when humans harm animals, they have a duty to repair the harm. Even if the human in the story did not harm the animal or species himself, he has a duty to make reparation as a member of the responsible group. As one boy argued to justify saving a rare chimpanzee, "They would be all right without us, but because of some of the things we've entered into the world, like pollution, whatever, they do need our help. Cause we've ruined it for them, they need our help to keep going." That boy and other stage 3 subjects thought that antisocial motives, such as human greed, threatened animals and animal groups and that humans with benevolent motives should assist in the recovery of animals and animal communities.

\section{Stage 4}

Human Reasoning. While stage 3 adolescents view the moral community as a personally connected group, stage 4 thinkers include unknown, abstract individuals within the social order. At stage 4 justice is no longer based on concrete or ideal reciprocity but instead centers on the relationships between individuals and the social system. Each individual's positive or negative contributions to society determine whether he merits positive or negative reciprocity. Rewards and punishments are administered through laws chosen by the society and applied equally to all society members. Preserving social values and institutions and maintaining the welfare of the social group are major motives for obedience to the current social order. Values are seen as relative to each society, and obligations to members of other societies are not defined by stage 4 thinkers.

Subjects taking the stage 4 perspective decided whether or not to violate the law for a dying woman based on her potential contributions to society, a system they valued beyond the worth of individual society members. For example, boys justified euthanasia if they believed that the woman's illness would prevent her from being a productive society member. Other boys opposed mercy killing if they thought that the woman had duties to benefit humanity that outweighed her personal problems. Stage 4 boys understood that social duties of individuals may conflict and sought to resolve clashes through laws. Laws, they believed, are needed to guide personal behavior past individual goals and toward actions promoting social welfare. Subjects opposed breaking laws against stealing or mercy killing due to potential negative group consequences, such as social instability. Boys feared that even permitting a well-intentioned person to break a law would set a dangerous precedent open to abuse and incompatible with maintaining the society's present values and order.

Animal Reasoning. Adolescents also used stage 4 reasoning to resolve animal dilemmas. Subjects emphasized the need for law obedience to protect the social values attributed to 
human life; boys feared that illegal mercy killing of an animal might lead to irresponsible killing of other animals, and, eventually, humans. Subjects opposed either stealing or mercy killing for animals if they perceived the acts as threatening the social order. For example, boys objected to stealing because without consistent application of laws, they expected society to become unstable. Boys also reasoned that even unfair laws about animal treatment should be obeyed because society legislates to promote the common good. Laws were chosen by the majority of humans and should not be undermined by either mercy killing or stealing.

Stage 4 responses also focused on the social values of animals. Boys argued for mercy killing if they believed that the dying animal would lose its ability to contribute to human society. Other boys defended euthanasia because they felt that animals never contribute to the social order. These boys believed that because animals cannot perform social functions, they have no value. For example, one boy defended mercy killing of a turkey, saying, "You're sustaining a great loss by taking a person's life because they're more intrinsically valuable to me. They're more valuable as human beings. They have personalities, logic, and they're more valuable to society. Whereas a farm turkey is just a farm turkey. It lives but it doesn't contribute to society."

In addition, stage 4 boys focused on the valuation and protection of the natural system as well as the social system. These subjects viewed nature, like society, as a system with value beyond the worth of the component individuals. For example, boys defended euthanizing common or rare animals if they could no longer contribute to the natural system through reproduction. Subjects also shared a conviction that the current natural order, like the social order, is ideal and should be maintained. Boys argued that social laws should also protect the natural system. Boys suggested laws giving humans negative duties not to manipulate natural processes and laws yielding positive duties to restore natural systems harmed by human actions. Human behaviors were assumed to be disruptive of environmental functions, whereas no animal behaviors or natural processes were seen as contrary to the natural order, even if extinction resulted. Social laws were viewed as necessary to prevent unnatural human impacts from degrading the order and values of the present natural system.

\section{Stage 5}

Human Reasoning. None of the human or animal responses involved stage 5 reasoning, but a stage description is included for comparative purposes. Kohlberg identifies the major cognitive advance of stage 5 thinking, usually achieved after adolescence, as a change from a law maintaining to a law making perspective. ${ }^{13}$ Stage 5 thinkers expect each person to take the perspectives of rational individuals, rather than the social system, and to seek to create rules and values ensuring protection of individual rights and welfare. Like stage 4 , most rules and values are viewed as relative to the social group. However, at stage 5 the individual is seen as obligated to follow rules and values because they were freely accepted as terms of a social contract. Stage 5 thinkers also argue that some principles and values are nonrelative. They believe that when rational individuals construct a rights or values hierarchy, the ultimate right or value is human life. A stage 5 thinker responding to the Heinz or Doctor dilemmas could be expected to justify either stealing or mercy killing because all other rights, such as property rights, presuppose rights to life, and the right to self-determination of life quality is inseparable from the right to life. The stage 5 concern for social contracts also might be used to resolve either dilemma. Support for stealing or mercy killing could be based on the social contract between the husband or the doctor with the dying woman, while rejection of law violation could be defended by emphasizing social contracts as a rational individual's agreement to protect society and individual rights through obedience to the society's laws.

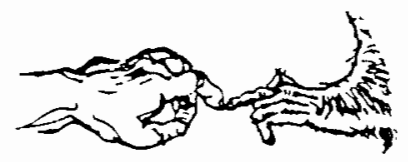




\section{$\underline{\text { Discussion }}$}

It would be premature to speculate on how individuals with stage 5 reasoning abilities would interpret justice toward animals. However, understanding how mature thinkers view social contracts and value hierarchies involving animals is not necessary to recognize that ethical concerns about animals emerge earlier in moral development. At least by early adolescence boys in this study were capable of using the same types of moral logic in addressing dilemmas about animal and human treatment. Although moral thinking about animals at stages 1 and 2 tended to focus on rules defined by authorities or on concrete personal needs, thinking about humans at early stages is similarly inflexible and egocentric. By stage 3 the boys' view of human justice as prosocial behavior aimed at maintaining community was also applied to their decisions about animal treatment. Stage 4 boys whose justice decisions about humans hinged on preserving societal order and values used equivalent criteria to interpret animal-related conflicts. Although some responses at each stage accorded little or no value to animals, boys at stage 1 through stage 4 did use their moral reasoning capacities to deliberate over the moral treatment of nonhuman animals.

For advocates of animal and environmental protection, the findings are particularly encouraging relative to the treatment of rare animals. Even as early as stage 2, boys could use their reasoning abilities to articulate arguments for preserving endangered species. For example, some stage 2 subjects advocated species preservation because of the pragmatic difficulties of replacing each species' benefits to humans. Stage 3 boys could comprehend the interdependence between closely associated animals and favored rare animal protection as a means of protecting animal communities. In addition, they viewed helping rare animals as an indication of prosocial character, a valued trait because of its importance in maintaining human communities. By stage 4 boys were able to understand complex, abstract relationships between humans, animals, and the environment. These subjects supported the use of social laws to protect rare animals and to maintain the current natural order. In fact, some stage 4 subjects espoused arguments that are remarkably similar to holistic environmental ethics, asserting that natural systems have value beyond the value of their component individuals.

Further research in to how females reason about animal treatment is essential to develop a comprehensive understanding of adolescents' moral reasoning about animals. However, the discovery that adolescent boys used the same moral logic to resolve human and animal dilemmas refutes Nash's argument that moral concern about animals and nature arises after mature recognition of individual human rights. Instead, these results indicate that each boy's attempts to understand his moral relationships with animals are concurrent with his efforts to decipher his moral relationships with humans. Children's struggles to define their moral obligations with animals are not a subsequent extension of human justice deliberations, occurring late or never in the average lifespan. Rather, resolving questions of animals and environmental ethics is a normal process in childhood development.

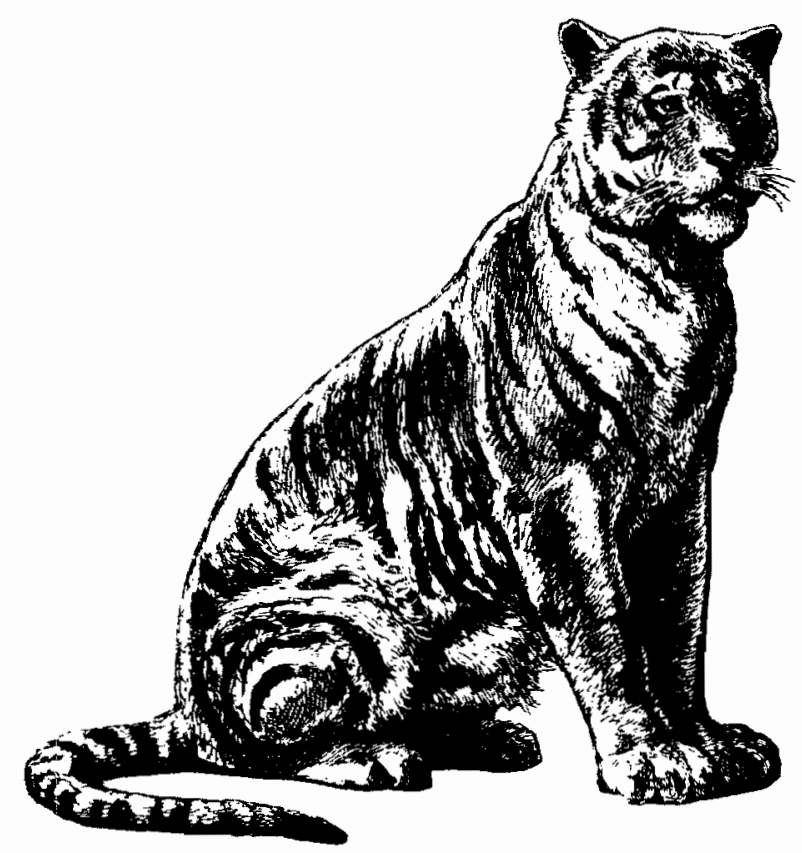


${ }^{1}$ Julie Dunlap, "Moral reasoning about animal treatment," Anthrozoos (in press, 1988).

${ }^{2}$ Lawrence Kohlberg, "The Current Formulation of the Theory," The Psychology of Moral Development (San Francisco: Harper \& Row, 1984).

${ }^{3}$ Anne Colby, Lawrence Kohlberg, John Gibbs, and Marcus Lieberman, "A Longitudinal Study of Moral Judgment," Monograph for the Society of Research in Child Development 48, no. 4 (Chicago: University of Chicago Press, 1983).

${ }^{4}$ Lawrence Kohlberg, "Moral Stages and Moralization," in Moral Development and Behavior, Thomas Lickona, editor (New York: Holt, Rinehart, Winston, 1976).

${ }^{5}$ Kohlberg, "Current Formulation of the Theory."

${ }^{6}$ John Rawls, A Theory of Justice (Cambridge, MA: Harvard University Press, 1971).
7 Roderick Nash, "Do Rocks Have Rights?" Center Magazine 10, no. 6 (1977): 2-12; Peter Singer, The Expanding Circle (New York: Farrar, Straus \& Giroux, 1981); Ernest Partridge, "Are We Ready for an Ecological Morality?" Environmental Ethics 4 (1982): 175-190.

${ }^{8}$ James Serpell, In the Company of Animals (Oxford: Basil Blackwell, 1986).

${ }^{9}$ Carol Gilligan, In a Different Voice (Cambridge, MA: Harvard University Press, 1982).

10 Anne Colby and Lawrence Kohlberg, eds., The Measurement of Moral Judgment (Cambridge: Cambridge University Press, 1987).

11 Colby et al., "A Longitudinal Study of Moral Judgment."

12 Kohlberg, "The Current Formulation of the Theory."

13 Ibid.

\section{$\underline{\text { Books Received }}$}

John Vyvyan

In Pity and In Anger:

A study of the Use of Animals in Science

Marblehead, MA: Micah Publications, 1988 (1969)

Introduction (Tom Regan), 164p, index

$\$ 9.95$ paper

John Vyvyan

The Dark Face of Science

Marblehead, MA: Micah Publications 1989 (1971)

$197 \mathrm{p}$, index

$\$ 9.95$ paper

\section{Wolves of Sorrow}

We are the forest shadows.

Silver whispers melting

out of sight before morning.

Our tribe is far older than yours.

We patiently hunted the land

before the days of steel death.

Our ancestors were a few who hid

from the fires 12,000 years ago;

Too wild and proud

to sit at the foot of man.

Lonely voices join

in a song like the wind in pain.

Our legacy

just a handful of dying echoes.

—Kathleen Malley 